\title{
ANALISIS PENGARUH LIMBAH GRC (GLASSFIBRE REINFORCED CEMENT) DAN ABU SEKAM PADI SEBAGAI BAHAN PENGGANTI SEBAGIAN MATERIAL BETON TERHADAP KUAT TEKAN BETON
}

\section{ANALYSIS OF THE EFFECT OF GRC WASTE (GLASSFIBRE REINFORCED CEMENT) AND RICE HUSK ASH AS SUBSTITUTES FOR PART OF CONCRETE MATERIALS ON THE COMPRESSIVE STRENGTH OF CONCRETE}

\author{
Luthfi Chandra Amarullah ${ }^{1}$, Sulfah Anjarwati ${ }^{2}$, Agus Salim ${ }^{3}$ \\ ${ }^{123}$ Program Studi S1 Teknik Sipil, Fakultas Teknik dan Sains \\ Universitas Muhammadiyah Purwokerto
}

\section{Informasi Artikel \\ Dikirim, \\ Direvisi, \\ Diterima,}

\section{Korespondensi Penulis:}

Luthfi Chandra Amarullah Program Studi Teknik Sipil Universitas Muhammadiyah Purwokerto

JL. K.H. Ahmad Dahlan Purwokerto, 53182

lchandraamarullah@gmail.com

\begin{abstract}
ABSTRAK
Di bidang konstruksi bangunan sendiri sudah banyak berkembang teknologi yang salah satunya adalah teknologi beton. Saat ini banyak penelitian-penelitian yang dilakukan oleh ahli sipil maupun mahasiswa untuk meningkatkan kualitas mutu beton. Dalam penelitian ini digunakan limbah GRC (Glassfibre Reinforced Cement) dan abu sekam padi. Penelitian ini dimaksudkan untuk mengetahui nilai kuat tekan beton dan perbandingan biaya produksi beton konvensional ataupun beton inovasi dengan tambahan limbah GRC, dan abu sekam yang sudah dipresentasekan sebagai pengganti agregat maupun semen dengan nilai fc' $32,25 \mathrm{Mpa}$. Adapun presentase campurannya limbah GRC sebanyak 7\% dari agregat kasar, dan abu sekam sebanyak 3\% dari semen. Dengan metode penelitian eksperimen dan direncanakan sesuai SNI 03-2834-2000 dengan fc' 32,35 Mpa. Pengujian beton dilakukan pada umur 7 hari lalu dikonversikan menjadi umur 28 hari. Hasil kuat tekan yang didapatkan pada umur 7 hari sebesar 24,77 Mpa, dengan konversi umur 28 hari sebesar 38,2 Mpa dan perbandingan harga beton inovasi lebih hemat sebanyak $\mathrm{Rp} 24.542,4$ untuk setiap $\mathrm{m}^{3}$ beton.
\end{abstract}

Kata Kunci : beton inovasi, limbah GRC, abu sekam padi, analisis biaya, kuat tekan

In the field of building construction itself, many technologies have been developed, one of which is concrete technology. At present there are many studies conducted by civilian experts and students to improve the quality of concrete. In this study used GRC (Glassfibre Reinforced Cement) waste and rice husk ash. This study is intended to determine the compressive strength value of concrete and the comparison of production costs of conventional concrete or innovative concrete with additional GRC waste, and husk ash that has been presented as a substitute for aggregate or cement with a value of $f_{c}$ ' $32.25 \mathrm{MPa}$. The percentage mix of GRC waste as much as $7 \%$ of coarse aggregate, and ash as much as 3\% of cement. With experimental research methods and planned according to SNI 03-2834-2000 with $\mathrm{fc}^{\prime} 32.35 \mathrm{MPa}$. Concrete testing is carried out at the age of 7 days and then converted to 28 days. The compressive strength results obtained at the age of 7 days amounted to 24,77 MPa, with a 28 day conversion of $38.2 \mathrm{MPa}$ and a comparison of the price of innovative concrete is more efficient as much as Rp. 24.542,4 for each $\mathrm{m}^{3}$ of conventional concrete.

Keyword: concrete innovation, GRC waste, waste rice husk, cost analysis, concrete's compressive strength. 


\section{PENDAHULUAN}

Penggunaan beton dalam dunia konstruksi sebagai pembentuk struktur sudah ada sejak dulu sampai sekarang. Banyak proyek konsruksi khususnya untuk pembuatan struktur menggunakan beton sebagai komponen utamanya. Hal ini akan menyebabkan penggunaan beton yang sangat besar dan biaya yang mahal. Belum lagi jika seseorang akan membangun rumah atau gedung yang bertingkat, tentu dibutuhkan pengecoran kolom beton dengan biaya yang cukup besar. Dengan membuat inovasi beton yang ekonomis dan tetap kuat tapi ramah lingkungan adalah salah satu cara agar dapat menghemat biaya yang dikeluarkan dalam membangun suatu bangunan.

Indonesia adalah negara produsen beras ketiga di dunia setelah China dan India (Kompas, 2015). Indonesia memproduksi beras sebesar 70,8 juta ton per tahun. Sekam padi merupakan bahan berligno- selulosa seperti biomassa lainnya namun mengandung silika yang tinggi. Kandungan kimia sekam padi terdiri atas $50 \%$ selulosa, $25-30 \%$ lignin, dan $15-20 \%$ silica (Ismail dan Waliuddin, 1996).

Sedangkan banyaknya gedung atau bangunan yang menggunakan GRC banyak ditemukan khususnya di Purwokerto, biasanya adalah gedung-gedung besar yang memerlukan komponen struktur yang ringan. Di Purwokerto sendiri banyak GRC yang pemanfaatannya masih kurang maksimal. Hal ini dibuktikan dengan adanya sisa-sisa material ataupun banyak runtuhan gedung yang menggunakan GRC.

Dengan begitu saya memperoleh sebuah inovasi bahwa harus ada komponen pengganti atau tambahan bahan penyusun beton dengan mix desain yang tepat, agar didapatkan beton yang memiliki kuat tekan tinggi, ekonomis, serta ramah lingkungan. Hal ini dapat dilakukan dengan cara menambahkan Limbah GRC, dan abu sekam sebagai bahan tambahan pada agregat dan semen.

\section{METODE PENELITIAN}

Metode yang digunakan dalam penelitian ini adalah metode eksperimen. penelitian eksperimen yang kami lakukan di Laboratorium Bahan Fakultas Teknik dan Sains Universitas Muhammadiyah Purwokerto. Pengujian beton dilakukan menggunakan benda uji berbentuk silinder dengan ukuran 15 x $30 \mathrm{~cm}$ sebanyak 3 sampel.

Langkah-langkah yang dilakukan dalam proses penelitian adalah sebagai berikut :

\section{Persiapan Material}

Material dalam penelitian ada material tambahan dan material umum. Material tambahan yang digunakan yaitu limbah GRC dan abu sekam padi. Material umum yang biasa digunakan dalam pembuatan beton yaitu : Agregat Halus, Agregat Kasar, Semen Portland, Air.

\section{Pengujian Material}

Pengujian Berat Jenis dan Penyerapan Air Agregat Halus

Untuk mengetahui berat jenis dan penyerapan air dalam peneliian ini dilakukan pehitungan sebagai berikut:

$$
\begin{aligned}
& \text { Berat jenis } S S D=\frac{A}{(C+A-D)} \ldots \ldots \ldots \ldots \ldots \ldots \ldots \ldots \ldots \ldots \ldots \\
& \text { Berat jenis keruh permukaan }=\frac{E}{(C+A-D)} . \\
& \text { Berat jenis semu (spesifik) }=\frac{E}{(C+E-D)} \ldots \ldots \\
& \text { Penyerapan Air }=\frac{A-E}{(E)} \times 100 \ldots \ldots \ldots \ldots \ldots \ldots . . .
\end{aligned}
$$

Keterangan :

$\mathrm{A}=$ berat benda uji dalam keadaan kering permukaan jenuh/SSD

$\mathrm{E}=$ berat benda uji kering oven, $($ gram)

$\mathrm{C}=$ berat piknometer berisi air, (gram)

$\mathrm{D}=$ berat piknometer berisi benda uji dan air, (gram)

\section{Pengujian Modulus Halus Butir}

Urutan pengujian modulus halus butir adalah sebagai berikut:

1. Siapkan benda uji yang digunakan adalah pasir

2. Menyiapkan satu set ayakan $4.75 \mathrm{~mm}, 2.36 \mathrm{~mm}, 1.18 \mathrm{~mm}, 0.6 \mathrm{~mm}, 0.3 \mathrm{~mm}, 0.15 \mathrm{~mm}$ dan sisa.

3. Menyiapkan alat getar ayakan, timbangan dengan ketelitian 0.1 gram, kuas pembersih ayakan, cawan

4. Masukkan pasir ke dalam set ayakan 
5. Pasanglah set ayakan kedalam alat getar ayakan kemudian getarkan selama 30 detik

6. Ambil ayakan dari atas alat getar, kemudian timbang lah pasir yang tertinggal dari masing-masing tingkat ayakan

Metode ini dilakukan perhitungan sebagai berikut:

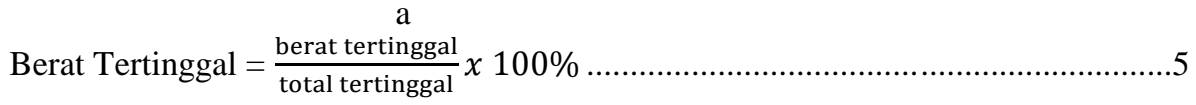

$$
\begin{aligned}
& \text { Berat Kumulatif }=\text { Berat tertinggal }+ \text { berat kumulatif diatasnya ......................6 }
\end{aligned}
$$

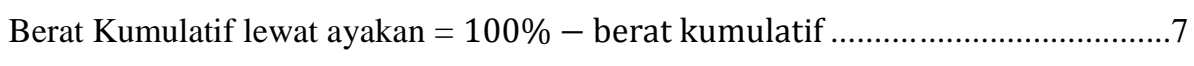

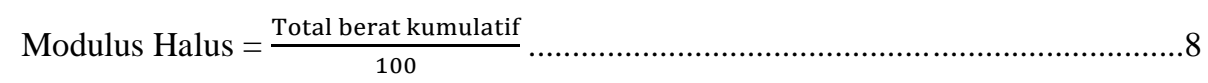

Pengujian Gradasi Agregat Halus

Urutan pengujian gradasi agregat halus adalah sebagai berikut:

1. Siapkan benda uji agregat halus.

2. Menyiapkan ayakan yang akan kita gunakan dan disusun dari atas dengan diameter ayakan yang paling besar mengacu (SNI 03-2834- 2000).

3. Masukkan pasir yang sudah ditimbang tadi kedalam ayakan yang paling atas Kemudian kita tutup ayakanya.

4. Masukan ayakan ke mesin penggetar selama \pm 5 menit

5. Setelah 5 menit, kita timbang pasir yang tertinggal di setiap ayakan.

Pemeriksaan Berat Jenis dan Penyerapan Air Agregat Kasar

Pemeriksaan berat jenis dan penyerapan air agregat kasar sebagai berikut:

1. Cuci terlebih dahulu benda uji untuk menghilangkan debu atau bahan- bahan lain yang masih tersisa atau menempel pada permukaan.

2. Keringkan benda uji dalam oven pada suhu $\left(110^{\circ} \pm 5\right)^{\circ} \mathrm{C}$ sampai berat tetap, sebagai catatan, bila penyerapan dan harga berat jenis digunakan dalam pekerjaan beton dimana agregatnya digunakan pada keadaan kadar air aslinya,maka tidak perlu dilakukan pengeringan dengan oven.

3. Dinginkan benda uji pada suhu kamar selama 1-3 jam, kemudian timbang dengan ketelitian 0,5 gram (BK).

4. Rendam benda uji dalam air pada suhu kamar selama $24 \pm 4$ jam.

5. Keluarkan benda uji dari air, lap dengan kain penyerap sampai selaput air pada permukaan hilang, untuk butiran yang besar pengeringan halus satu persatu.

\section{Pemeriksaan Gradasi Agregar Kasar}

Urutan pemeriksaan gradasi agregat kasar adalah sebagai berikut:

1. Benda uji dikeringkan dalam oven dengan suhu $(110 \pm 5) \mathrm{C} 0$, sampai berat tetap.

2. Menyiapkan ayakan yang akan kita gunakan dan disusun dari atas dengan diameter ayakan yang paling besar mengacu (SNI 03-2834-2000).

3. Sering benda uji lewat susunan saringan dengan ukuran saringan paling besar ditempatkan paling atas. Saringan diguncang dengan tangan atau mesin pengguncang selama 15 menit.

4. Hitunglah persentase benda berat uji yang tertahan di atas masingmasing saringan terhadap berat total benda uji setelah disaring.(SNI 03- 1968-1990).

\section{Abu Sekam Padi}

Abu sekam padi yang diambil dari limbah hasil batu bata di Desa Pliken diambil lalu di ayak dengan lolos saringan no. 200, kemudian material serat dan abu tersebut digunakan sebagai bahan pengganti sebagian semen dalam campuran beton.

\section{Limbah GRC}

Limbah GRC yang merupakan hasil reruntuhan bangunan yang ada di Purwokerto diambil kemudian di pecah untuk ukuran yang masih besar menggunakan palu lalu di saring dengan maksimal agregat ukuran $2 \mathrm{~cm}$. 


\section{Perencanaan Campuran Beton (Mix Design)}

Sebelum pelaksanaan pembuatan benda uji, terlebih dahulu membuat Perencanaan Mix Design beton sesuai dengan panduan SNI - 03 - 2834 -2000. Tujuan dari perencanaan Mix Design beton adalah untuk menentukan proporsi campuran semen, agregat kasar, agregat halus dan air sehingga dihasilkan beton yang berkualitas baik dan sesuai dengan rencana dari penelitian ini yaitu mutu (32,25 MPa).

\section{Pembuatan Benda Uji}

Pembuatan benda uji dilakukan dengan cetakan silinder berdiameter $15 \mathrm{~cm}$ dan tinggi $30 \mathrm{~cm}$ yang terdapat 3 sampel. Berikut langkah langkah dalam pembuatan benda uji dalam penelitian ini.

1. Siapkan alat dan bahan yang digunakan untuk pembuatan benda uji.

2. Timbang material dalam pembuatan beton yang telah disiapkan, dsalam penimbangan material sesuai dengan mix design yang sudah dibuat untuk penelitian ini.

3. Bahan yang sudah ditimbang lalu dicampur dalam molen dari mulai urutan agregat kasar, agregat halus, semen, abu sekam padi, limbah grc, lalu setalah tercampur ditambahkan air. Di aduk dalam mixer sehingga menjadi homogen.

\section{Uji Slump}

Slump dilakukan untuk mengukur kekentalan adukan beton yang dinyatakan dalam mm ditentukan dengan alat kerucut Abrams. Langkah uji slump dilakukan sebagai berikut:

a. Kerucut Abrams dan plat disiapkan dan dibasahi air agar sedikit licin.

b. Kerucut Abrams diletakan tepat pada tengah-tengah papan.

c. Tuangkan $1 / 3$ beton segar, kemudian di tusuk-tusuk sebanyak 30 kali.

d. Lakukan langkah ke 3 sampai kerucut Abram penuh.

e. Angkat kerucut Abrams.

f. Hitung perbedaan tinggi menggunakan penggaris.

\section{Uji Kuat Tekan Beton}

Pengujian kuat tekan dilakukan setelah beton berumur 7 hari kemudian nilai dikonversi ke 28 hari. Benda uji yang digunakan adalah beton berbentuk silinder dengan ukuran diameter $15 \mathrm{~cm}$ dan tinggi $30 \mathrm{~cm}$ sebanyak 3 buah. Alat uji yang digunakan adalah Compression Testing Machine.

\section{HASIL DAN PEMBAHASAN}

\subsection{Pemeriksaan Berat Jenis dan Penyerapan Air}

Tabel 1. Hasil Pemeriksaan Berat Jenis dan Penyerapan Air Agregat Halus

\begin{tabular}{|c|c|c|c|c|c|}
\hline No & \multicolumn{2}{|l|}{ Jenis Pemeriksaan } & Satuan & $\mathbf{I}$ & II \\
\hline 1 & Berat Kering Permukaan & $\mathrm{A}^{\prime}$ & Gram & 500 & 500 \\
\hline 2 & Berat Contoh Kering Oven & A & Gram & 491.3 & 492.4 \\
\hline 3 & Berat Botol + Pasir & B & Gram & 656.3 & 658.1 \\
\hline 4 & Berat Botol + Contoh + Air & $\mathrm{C}$ & Gram & 958.2 & 960.4 \\
\hline \multirow{2}{*}{5} & \multirow{2}{*}{ Berat Jenis Bulk (Kering Oven) } & \multirow{2}{*}{$\mathrm{A} /\left(\mathrm{B}+\mathrm{A}^{\prime}-\mathrm{C}\right)$} & & 2.48 & 2.49 \\
\hline & & & Rata-rata & \multicolumn{2}{|c|}{2.485} \\
\hline \multirow{2}{*}{6} & \multirow{2}{*}{ Berat Jenis Bulk (Kering Permukaan) } & \multirow{2}{*}{$500 /(B+A-C)$} & & 2.64 & 2.63 \\
\hline & & & Rata-rata & \multicolumn{2}{|c|}{2.635} \\
\hline \multirow{2}{*}{7} & \multirow{2}{*}{ Berat Jenis Semu } & \multirow{2}{*}{$\mathrm{A} /(\mathrm{B}+\mathrm{A}-\mathrm{C})$} & & 2.59 & 2.59 \\
\hline & & & Rata-rata & \multicolumn{2}{|c|}{2.59} \\
\hline \multirow{2}{*}{8} & \multirow{2}{*}{ Penyerapan Air } & \multirow{2}{*}{$\begin{array}{l}((500- \\
\mathrm{A}) / \mathrm{A})^{*} 100 \%\end{array}$} & & 1.74 & 1.52 \\
\hline & & & Rata-rata & \multicolumn{2}{|c|}{1.63} \\
\hline
\end{tabular}

\subsection{Pemeriksaan Kadar Lumpur}

Tabel 2. Hasil Pemeriksaan Kadar Lumpur Agregat Halus

\begin{tabular}{cllrr}
\hline No & \multicolumn{1}{c}{ Jenis Pemeriksaan } & Satuan & \multicolumn{1}{c}{ I } & \multicolumn{1}{c}{ II } \\
\hline 1 & Berat contoh kering sebelum dicuci & Gram & 1000 & 1000 \\
2 & Berat contoh setelah dicuci & Gram & 989.2 & 982.6 \\
3 & Berat yang hilang & Gram & 10.8 & 17.4
\end{tabular}

CIVeng Vol.2, No.1, Januari $2021: 29 \sim 36$ 


\begin{tabular}{cllcc}
4 & Presentase berat yang hilang $=(1-2) /(1) \times 100 \%$ & $\%$ & 1.08 & 1.74 \\
5 & Hasil rata-rata & $\%$ & 1.41 & \\
\hline Sumber : Analisis 2018
\end{tabular}

\subsection{Pemeriksaan Gradasi Agregat Halus}

Tabel 3. Hasil Pemeriksaan Gradasi Agregat Halus

\begin{tabular}{cccccccc}
\hline & \multicolumn{3}{c}{ UKURAN AYAKAN } & \multicolumn{3}{c}{ Berat Tertahan } & \multicolumn{2}{c}{ Berat Lolos } \\
$(\mathbf{m m})$ & SNI & ASTM & inch & gr & \% & gr & \% \\
\hline 9,5 & 9,6 & $3 / 8$ inch & 0,375 & 0 & 0,00 & 500 & 100,00 \\
4,75 & 4,8 & no.4 & 0,187 & 0 & 0,00 & 500 & 100,00 \\
2,36 & 2,4 & no.8 & 0,0937 & 0,59 & 0,118 & 499,41 & 99,882 \\
1,18 & 1,2 & no.16 & 0,469 & 61,94 & 12,388 & 437,47 & 87,494 \\
0,6 & 0,6 & no.30 & 0,0234 & 161,44 & 32,288 & 276,03 & 55,206 \\
0,3 & 0,3 & no.50 & 0,0117 & 150,24 & 30,048 & 125,79 & 25,158 \\
0,15 & 0,15 & no.100 & 0,0059 & 116,19 & 23,238 & 9,6 & 1,92 \\
& & Pan & & 9,6 & 1,92 & 0 & 0 \\
& & & & 500 & 100 & & \\
\hline
\end{tabular}

Sumber : Analisis 2018

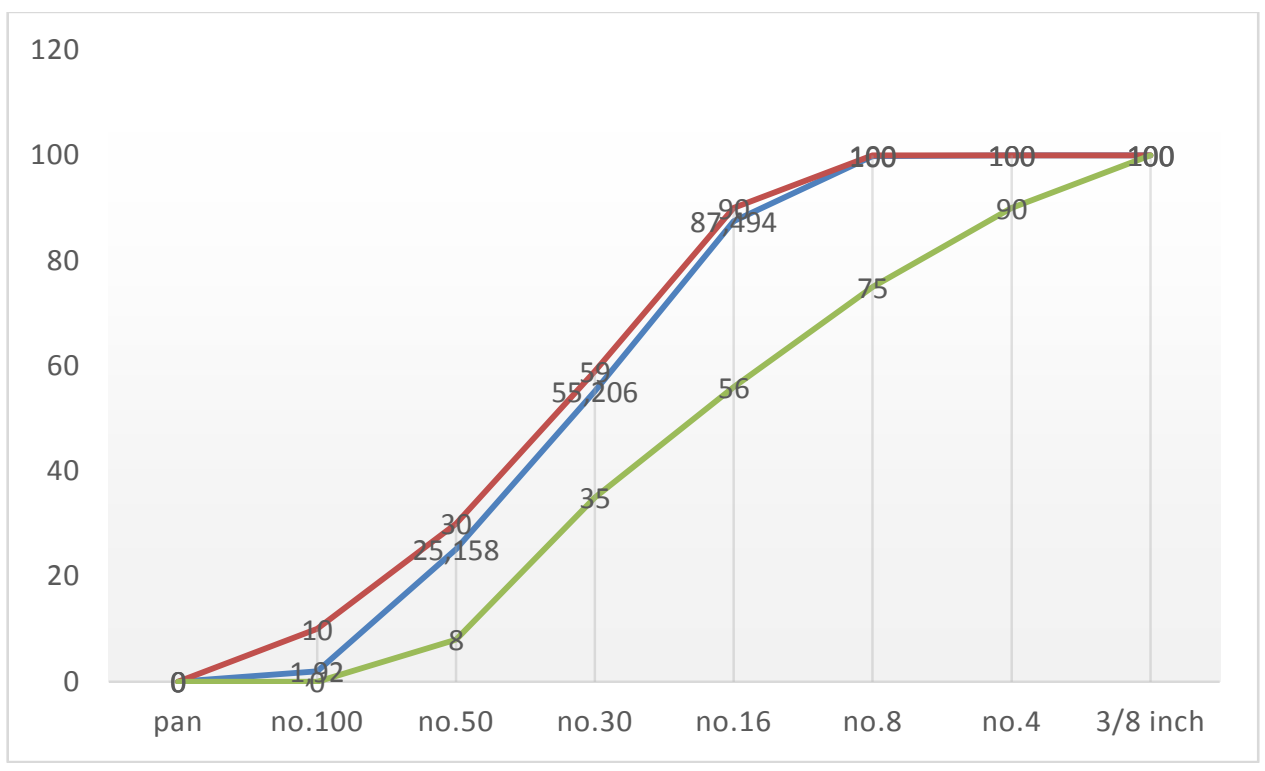

Gambar 1. Grafik Batas Gradasi Agregat Halus Sumber : Analisis 2018

\subsection{Analisa Saringan Agregat Kasar}

Tabel 4. Hasil Pemeriksaan Gradasi Agregat Kasar

\begin{tabular}{ccccrrrrr}
\hline & \multicolumn{3}{c}{ UKURAN AYAKAN } & \multicolumn{3}{c}{ Berat Tertahan } & \multicolumn{2}{c}{ Berat Lolos } \\
$(\mathbf{m m})$ & SNI & ASTM & inch & gr & \% & \multicolumn{1}{c}{ gr } & \multicolumn{1}{c}{$\%$} \\
\hline 75 & 76 & 3 in & 3 & 0 & 0 & 2000 & 100 \\
37,5 & 38 & $11 / 2$ in & 1,5 & 0 & 0 & 2000 & 100 \\
19 & 19 & $3 / 4$ in & 0,75 & 698 & 34,9 & 1302 & 65,1 \\
9,5 & 9,6 & $3 / 8$ in & 0,375 & 807,24 & 40,362 & 494,76 & 38 \\
4,75 & 4,8 & no.4 & 0,187 & 487,84 & 24,392 & 6,92 & 1,398658 \\
& & pan & & 6,92 & 0,346 & 0 & 0 \\
& & Jumlah & & 2000 & 100 & & \\
\hline
\end{tabular}

Sumber : Analisis 2018 


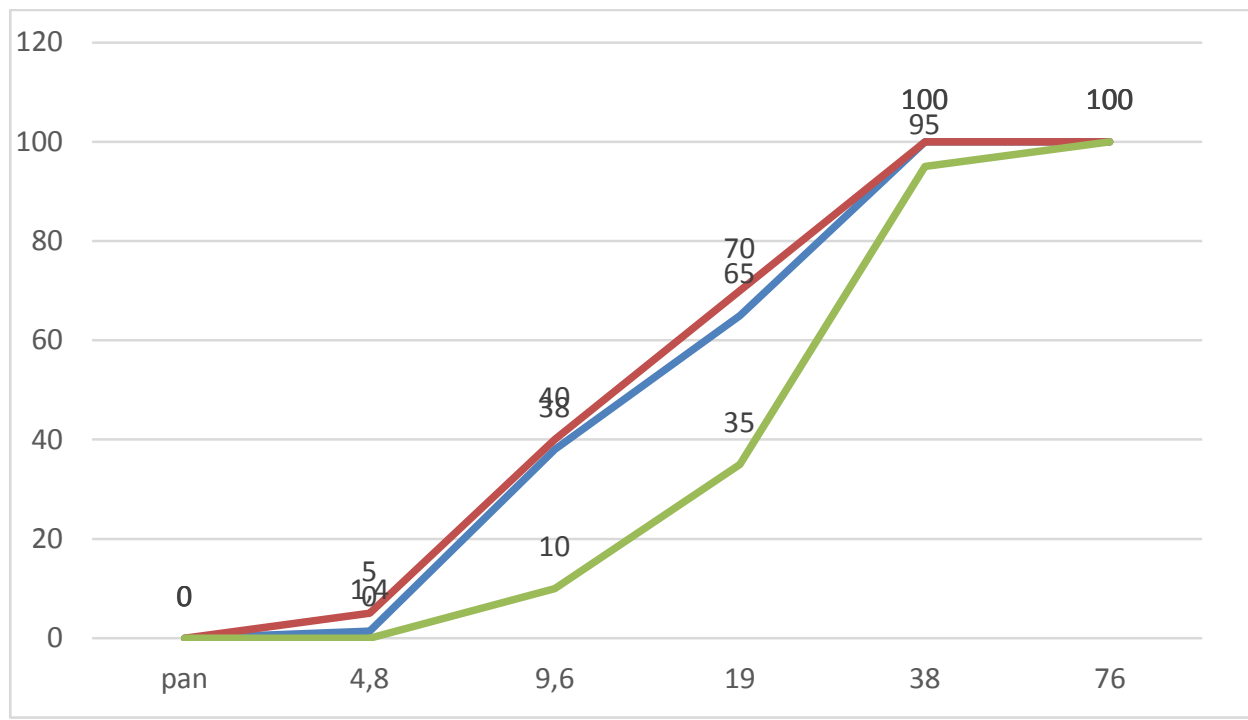

Gambar 2. Grafik Gradasi Agregat Kasar Sumber : Analisis 2018

\subsection{Berat Jenis Agregat Kasar}

Tabel 5. Hasil Pemeriksaan Berat Jenis dan Penyerapan Agregat Kasar

\begin{tabular}{|c|c|c|c|c|}
\hline Pengujian & Notasi & Satuan & $\mathbf{I}$ & II \\
\hline Berat Kering Contoh Oven & A & Gram & 1000 & 1000 \\
\hline Berat Kering Permukaan & B & Gram & 1011 & 1020 \\
\hline Berat Contoh Dalam Air & $\mathrm{C}$ & Gram & 613 & 625 \\
\hline \multirow{2}{*}{ Berat Jenis Bulk (kering oven) } & \multirow{2}{*}{$\mathrm{A} /(\mathrm{B}-\mathrm{C})$} & & 2.51 & 2.53 \\
\hline & & Rata-rata & & \\
\hline \multirow{2}{*}{ Berat Jenis Bulk (Kering Permukaan) } & \multirow{2}{*}{$\mathrm{B} /(\mathrm{B}-\mathrm{C})$} & & 2.54 & 2.58 \\
\hline & & Rata-rata & & \\
\hline \multirow{2}{*}{ Berat Jenis Semu } & \multirow{2}{*}{$\mathrm{A} /(\mathrm{A}-\mathrm{C})$} & & 2.58 & 2.67 \\
\hline & & Rata-rata & & \\
\hline \multirow{2}{*}{ Penyerapan Air } & \multirow{2}{*}{$((\mathrm{B}-\mathrm{A}) / \mathrm{A}) * 100 \%$} & & 1.1 & 2 \\
\hline & & Rata-rata & & \\
\hline
\end{tabular}

Sumber : Analisis 2018

\subsection{Perencanaan Mix Design}

Perencanaan Mix Design berguna untuk menentukan proporsi semen, agregat kasar, agregat halus, air, abu sekam, dan limbah GRC agar didapat hasil beton yang sesuai dengan spesifikasi yang diinginkan berdasarkan SNI 03-2834 2000.

Tabel 6. Formulir Perencanaan Mix Design

\begin{tabular}{llll}
\hline No. & \multicolumn{1}{c}{ Uraian } & \multicolumn{1}{c}{ Nilai } & \multicolumn{1}{c}{ Satuan } \\
\hline 1 & Kuat tekan rencana dalam 28 hari & 32.25 & $\mathrm{Mpa}$ \\
2 & Deviasi Standar (s) & 2.8 & $\mathrm{Mpa}$ \\
3 & Margin (sr) & 4.592 & $\mathrm{Mpa}$ \\
4 & Kuat tekan rata-rata yang direncanakan (maksimum) (f'cr) & 36.842 & $\mathrm{Mpa}$ \\
5 & Jenis semen & PCC/1 & \\
6 & Jenis Agregat kasar (alami/pecah) & Pecah & \\
7 & Jenis Agregat halus (alami/pecah) & Alami (serayu) & \\
8 & Faktor air semen & 0.39 & \\
9 & Nilai slump & $30-60$ & \\
10 & Ukuran maksimum agregat kasar & 40 & $\mathrm{Mm}$ \\
11 & Kebutuhan air penyesuaian admixture & 190 & $\mathrm{liter} / \mathrm{m}^{3}$ \\
12 & Kebutuhan semen & 487.179 & $\mathrm{~kg} / \mathrm{m}^{3}$ \\
15 & Daerah gradasi agregat halus & daerah/zona 2 & $\mathrm{kg} / \mathrm{m}^{3}$ \\
\hline
\end{tabular}

CIVeng Vol.2, No.1, Januari 2021 : 29 36 


\begin{tabular}{clll}
16 & Persen berat agregat halus & $30 \%$ & $\mathrm{~kg} / \mathrm{m}^{3}$ \\
17 & Berat jenis agregat campuran & 2.58 & $\mathrm{~kg} / \mathrm{m}^{3}$ \\
16 & Berat jenis beton & 2,375 & $\mathrm{~kg} / \mathrm{m}^{3}$ \\
17 & Kebutuhan agregat & 1697.8 & $\mathrm{~kg} / \mathrm{m}^{3}$ \\
18 & Kebutuhan agregat halus & 509,3 & $\mathrm{~kg} / \mathrm{m}^{3}$ \\
19 & Kebutuhan agregat kasar & 1188,5 & $\mathrm{~kg} / \mathrm{m}^{3}$ \\
\hline Sumber & Analisis 2018
\end{tabular}

Tabel 7. Proporsi Campuran Per $\mathrm{m}^{3}$

\begin{tabular}{lccrrr}
\hline \multicolumn{1}{c}{ Volume per $\mathbf{~ m}^{\mathbf{3}}$} & $\begin{array}{c}\text { Berat } \\
\text { total }\end{array}$ & Air (L) & Semen (Kg) & $\begin{array}{c}\text { Agregat } \\
\text { Halus (Kg) }\end{array}$ & $\begin{array}{c}\text { Agregat } \\
\text { Kasar (Kg) }\end{array}$ \\
\hline Teoritis & 2400 & 190 & 487.179 & 509.346 & 1188.47 \\
Terkoreksi & & 217.31 & 487.179 & 509.346 & 1188.47 \\
\hline Sumber: Analisis 2018 & & &
\end{tabular}

Tabel 8. Proporsi Campuran Beton Inovasi Per Benda Uji

\begin{tabular}{ccccccc}
\hline Benda Uji & $\begin{array}{c}\text { Semen } \\
(\mathbf{K g})\end{array}$ & $\begin{array}{c}\text { Pasir } \\
(\mathbf{K g})\end{array}$ & $\begin{array}{c}\text { Air } \\
(\mathbf{L})\end{array}$ & $\begin{array}{c}\text { Kerikil } \\
(\mathbf{K g})\end{array}$ & $\begin{array}{c}\text { Abu } \\
\text { Sekam } \\
(\mathbf{K g})\end{array}$ & $\begin{array}{c}\text { Limbah } \\
\mathbf{G R C} \\
(\mathbf{K g})\end{array}$ \\
\hline $\begin{array}{c}\text { Silinder } \varnothing \\
15 \mathrm{~cm} \times 30 \mathrm{~cm}\end{array}$ & 2.5 & 2.69 & 1.15 & 5.15 & 0.077 & 0.441 \\
\hline Sumber : Analisis 2018 & & & &
\end{tabular}

\subsection{Hasil Pengujian Kuat tekan Beton}

Tabel 9. Hasil Uji Kuat Tekan Beton

\begin{tabular}{cccccc}
\hline & Satuan & sampel 1 & sampel 2 & sampel 3 & rata -rata \\
\hline hasil beban yang terbaca & Ton & 45 & 46 & 43 & 44,6 \\
luas silinder 15 x 30 & $\mathrm{Kg}$ & 45.000 & 46.000 & 43.000 & 44.600 \\
kuat tekan umur 7 hari & $\mathrm{cm} 2$ & 176,25 & 176,25 & 176,25 & 176,25 \\
konversi kuat tekan 28 hari & $\mathrm{Mpa}$ & 24,96 & 25,52 & 23,85 & 24,77 \\
\hline Sumber : Analisis 2018 & $\mathrm{Mpa}$ & 38,4 & 39,525 & 36,7 & 38,2 \\
\hline
\end{tabular}

\section{Grafik Kuat Tekan (Mpa)}

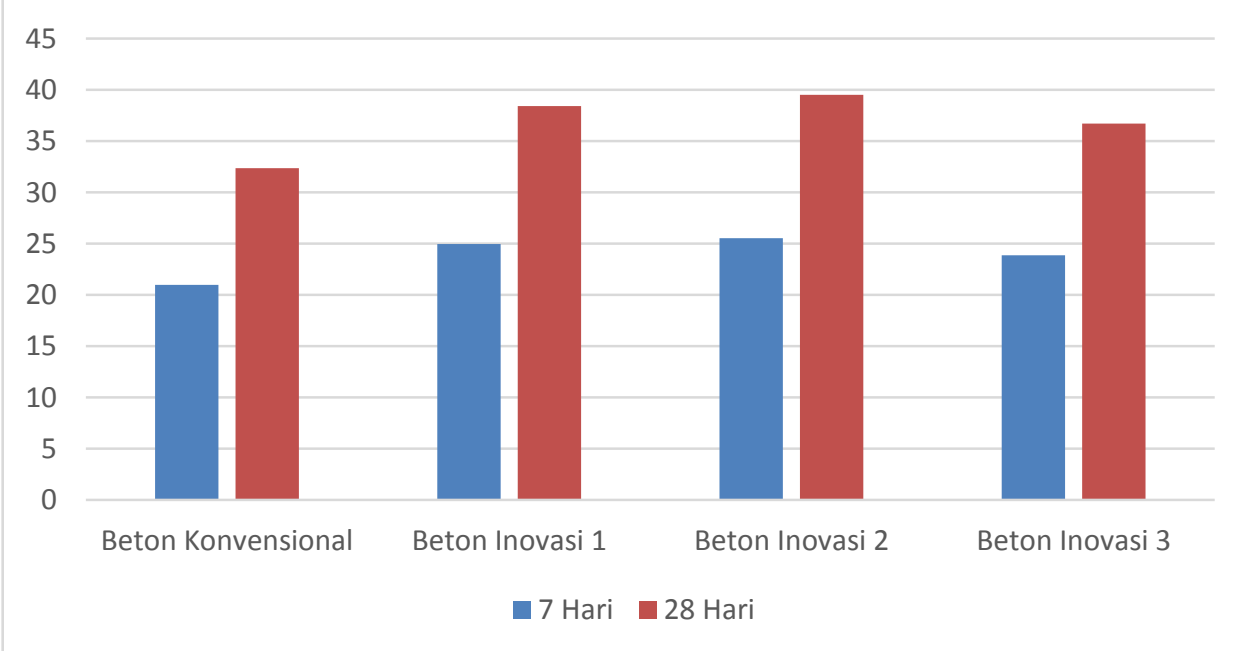

Gambar 3. Grafik Kuat Tekan Beton Sumber : Analisis 2018 


\subsection{Rincian Biaya Per $\mathbf{m}^{3}$}

Tabel 10. Rincian Biaya Beton Inovasi per $\mathrm{m}^{3}$

\begin{tabular}{lcclrlr}
\hline \multicolumn{1}{c}{ Material } & ${\text { Kadar Per } \mathbf{~ m}^{\mathbf{3}}}$ & Unit & \multicolumn{2}{c}{ Harga Satuan (Rp) } & \multicolumn{1}{c}{ Total (Rp) } \\
\hline Kerikil & 1105,281 & $\mathrm{Kg}$ & $\mathrm{Rp}$ & 200,00 & $\mathrm{Rp}$ & $221.056,23$ \\
Pasir & 509,346 & $\mathrm{Kg}$ & $\mathrm{Rp}$ & 200,00 & $\mathrm{Rp}$ & $115.719,62$ \\
Semen & 472,564 & $\mathrm{Kg}$ & $\mathrm{Rp}$ & $1.120,00$ & $\mathrm{Rp}$ & $529.271,79$ \\
Abu Sekam & 14,6153 & $\mathrm{Kg}$ & $\mathrm{Rp}$ & 10,00 & $\mathrm{Rp}$ & 146,15385 \\
Limbah GRC & 83,193 & $\mathrm{Kg}$ & $\mathrm{Rp}$ & 100,00 & $\mathrm{Rp}$ & $8.319,3205$ \\
Air & 217,318 & $\mathrm{~L}$ & $\mathrm{Rp}$ & 0,00 & $\mathrm{Rp}$ & 0,00 \\
& Jumlah & & & & $\mathrm{Rp}$ & $860.662,73$ \\
\hline
\end{tabular}

Sumber : Analisis 2018

Tabel 11. Rincian Biaya Beton Konvensional per $\mathrm{m}^{3}$

\begin{tabular}{lcccrrr}
\hline \multicolumn{1}{c}{ Material } & ${\text { Kadar Per } \mathbf{~ m}^{\mathbf{3}}}$ & Unit & Harga Satuan (Rp) & \multicolumn{1}{c}{ Total (Rp) } \\
\hline Kerikil & 1188,474 & $\mathrm{Kg}$ & $\mathrm{Rp}$ & 200,00 & $\mathrm{Rp}$ & 237694,9 \\
Pasir & 508,436 & $\mathrm{Kg}$ & $\mathrm{Rp}$ & 200,00 & $\mathrm{Rp}$ & 101869,2 \\
Semen & 487,179 & $\mathrm{Kg}$ & $\mathrm{Rp}$ & 1120,00 & $\mathrm{Rp}$ & 545641 \\
Air & 217,318 & $\mathrm{~L}$ & $\mathrm{Rp}$ & 0,00 & $\mathrm{Rp}$ & 0,00 \\
& Jumlah & & & & $\mathrm{Rp}$ & 885205,1 \\
\hline
\end{tabular}

Sumber : Analisis 2018

\section{KESIMPULAN}

Berdasarkan penelitian ini beton inovasi dengan limbah GRC dan abu sekam padi memiliki pengaruh kenaikan kuat tekan sebesar 18,44 \% dari beton konvensional. Beton konvensional memerlukan biaya pembuatan Rp 885.205,1 untuk setiap $\mathrm{m} 3$ sedangkan beton inovasi hanya memerlukan biaya pembuatan sebanyak Rp 860.662,73 untuk setaip $\mathrm{m} 3$ beton, inovasi ini lebih ekonomis dalam biaya produksi dengan menghemat sebanyak Rp.24.542,4 untuk setiap m3 beton.

\section{DAFTAR PUSTAKA}

[1] Alfredo, Marchin. 2012. Studi Kuat tekan Beton normal Mutu Sedang dengan Campuran Abu Sekam Padi (RHA) dan Limbah Adukan Beton (CSW).

[2] artiKON. 2015. Komposisi GRC dan Berat Rata-Rata Produk GRC Panel Cladding. Artikel). Tersedia di: https://grcartikon.co.id/komposisi-grc/

[3] Badan Standarisasi Nasional. 2000. Tata Cara Pembuatan Rencana Campuran Beton Normal. SK SNI 032834-2000

[4] Chu-Kia Wang, Dkk.1993. Desain Beton Bertulang. Erlangga : Jakarta.

[5] Haryadi. 2006. Abu Padi Sekam di Indonesia (Artikel). Tersedia di: https://subhanesa.wordpress.com/2013/04/03/abusekam-padi-indonesia/

[6] Jokrodimuljo, K. 1997. Teknologi Beton. Jurusan Teknik Sipil Fakultas Teknik. Yogyakarta: Universitas Gadjah Mada [Jurnal]

[7] Mulyadi, Asri. 2011. Pengaruh Penambahan Kapur dan Abu Layang terhadap Mortar dengan Uji Kuat Tekan serta Serapan Air pada Bata Beton Bertulang. Jurnal Teknik Sipil Fakultas Teknik Universitas Palembang. Volume 1, Nomor 1, Agustus 2011

[8] Murdock, L.J. 1999. Bahan Dan Praktek Beton. Erlangga : Jakarta.

[9] Okamur, H., Maekawa, K. and Ozawa, K. 1993. High Performance Concrete. [Jurnal] Sutami, 1971, Kontruksi Beton Indonesia, Badan Penerbit Pekerdjaan Umum, Djakarta 